\title{
THE NEWLY DISCOVERED GOBLIN SHARK OF JAPAN
}

\section{BY DR. L HUSSAKOF}

Every now and then the zoological world is startled by the announcement of the discovery in Japanese waters of some very rare or very ancient type of animal. So often, is this the case that zoologists have come to look upon the deep waters of Japan as a sort of naturalists' wonder-realm - a preserve in which live all manner of interesting animals, some of them of an archaic type long extinct in other parts of the world. The expectation of remarkable discoveries in these waters is so strong that I have heard a distinguiched American zoologist, who is himself well acquainted with Japanese waters, say that he would not be greatly surprised to hear some day that a real Mosasaur or Ichthyosaur had been hooked in the depths of Kuro Shiwo, or warm "Black Current" of Japan.

It is in these waters that Japanese fishermen occasionally take on their lines a shark whose grotesqueness has won him among natives the name of Tenguzame, or goblin shark. One of these "goblins" came into the hands of President David Starr Jordan of Leland Stanford University a dozen years ago and was at once recognized as an interesting archaic type whose close relatives had long since become extinct. President Jordan described it under the name of Mitsukurina owstoni-the name being given to honor at the same time the late Prof. Kakichi Mitsukuri, who for a quarter of a century was the leading light of Japanese zoology, and Mr. Alan Owston, a natural history dealer of Yokohama, who was instrumental in securing the specimen. This name, by the way, does not stand at the present day, but must be replaced by Scapanorhynchus-a name which had previously been applied to the teeth of the extinct species of this type of shark found in the rocks of the Chalk period, in different parts of the world. In accordance with scientific usage, therefore the Japanese shark described by President Jordan must now be known as Scapanorhynchus owstoni.

It is now to be recorded that a second species of goblin shark has turned up in a most unexpected way. It happened thus: All of the sharks caught in Japan in the past years and sent to the variou $\mathrm{museums}$ - about twenty in all-were looked upon as belonging to the same longing to the same species, S. owstoni. No one had ever thought of comparing several specimens; in fact, these sharks are so rare in museums that comparison is that comparison $i$ the question. It was the question. therefore a pleasure for the writer to have had the opportunity of comparing several specimens in the collection at Columbia lections at Columbia American Museum of American Museum of
Natural History, and Natural History, and to find among them a new species of the goblin shark. This has recently been described in the Bulletin of the American tin of the American Museum of Natural
History as Scapanorhynchus jordani-the specific name being

given in honor of President Jordan, our greatest authority on the fish of Japan.

Now to come to the fish himself: As seen in the illustration (Fig. 1) the new shark is certainly grotesque, well deserving his sobriquet "goblin." Th largest specimen in this country is one in the National Museum at Washington, measuring over eleven feet; and the species probably attains a length of fifteen. Fortunately it is not given to frequenting the bathing beach, but keeps to deeper waters-usually about fifty fathoms. As is generally the case with fish from deeper water, this shark is soft and pliable. Even afte hardening in a preservative for several months, it can be rolled into a ball. The most remarkable feature is the curiously elongated "nose" (shown in Fig. 2). It is this, together with its protruding jaw and small beady eyes, that gives the shark that ugly by specialists to distinguish species of fish.

\section{Pipe, Cigaretie. and Clgar.}

appearance. The teeth (Fig. 3) are sharp and slender, each like the pointed end of an awl. They constitute a most effective weapon, which must be fingered with discretion even on the laboratory table. As to the peculiar anatomical characters, suffice it to say that in the total make-up it is so different from all other sharks that President Jordan was at first inclined to classify the genus to which it belongs in a special family by itself.

As to the differences between the new species and the one already known, we need say only a few words.

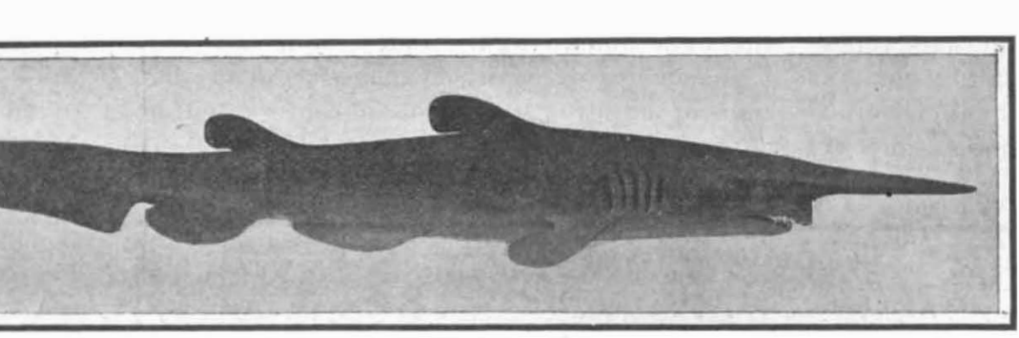

1.-The newly discovered goblin shark (Seapanorhynchus jordani). ter of fact, carbon monoxide is invariably found in all tobacco smoke, and that circumstance should be sufficient to warn all smokers against inhaling it persistently. Theories as to what happens in the combustion of tobacco in the various ways it is smoked next took into account the extent to which condensation products were formed and retained in the tobacco. The most effective condenser, of course, is the pipe, and there can be little doubt that owing to the length of the stem a comparatively small proportion of these condensation products reaches the mouth. In the cigar, on the contrary, the condensing process has a tendency to travel throughout the cigar; at all events, as the cigar gets shorter the condensed product area gradually reaches the mouth and eventually the products are conveyed there by the heat of the burning end. It has been said by connoisseurs that no cigar is worth smoking after one-half of it has been consumed, which seems to be a practical realization of theoretiThe pictures show the differences at a glance even to the layman in matters ichthyological. The new form (lower picture) is distinguished by a much less protruding jaw, by a very much smaller spiracle (the minute accessory gill-pore seen at some distance back of the eye), and by the fact that the eye is situated opposite the middle of the jaw instead of back of it These features are quite sufficient, in the opmion of experts, for separating our goblin as a distinct "kind." To the general reader they may perhaps be of interest as examples of the degrees of difference which are used

The question as to which of the three forms of anoking, the pipe, the cigarette, or the cigar, introduces the greatest proportion of nicotine into the smoker's system has never obtained a completely decisive answer, although it has received considerable discussion from time to time. At one time it was freely asserted that the tobacco which contained the cal considerations very suitable for application by millionaires. Again, a cigar that has been partially smoked and then allowed to go out is decidedly unpleasant when re-iit owing doubtless to the spread of condensation products to the mouth end. In case of the pipe, the burning area is always in the same place; it never comes near the mouth, and therefore the probability is that the condensation products do not reach the mouth in, at any rate, appreciable quantities. In the cigarette the condensation products eventually reach the mouth, but there is in this case less charce of condensation products forming since the combustion is unhampered, the tobacco being freely in contact with the air. The question of moisture, however, must not be left out in these considerations, for it is obvious that damp tobacco will form condensation products more readily than dry tobacco. It is probable, therefore, that a dry cigar or cigarette gives off less poisonous products but not everyone smok choice a new cigar or an old cigarette. It is reasonable to conclude that the amount of nicotine reaching the mouth does not neces. sarily depend on the amount in the tobacco but on the form in which it is smoked. In drawing this conclusion regard must, of course, be had to the quantity of tobacco smoked, but if the conclusion is correct, the pipe would come first as the least harmful form of to bacco smoking, then the cigarette, and lastly the cigar.-Lancet.

It has often been remarked that the centers of seismic and volcanic activity move slowly westward. In a recent issue of the Physikalische $\mathrm{Z}$ e i t schrift, H. Wehne adopts this belief and endeavors to explain the westward move ment by reviving the old hypothesis of THE NEWLY DISCOVERED GOBLIN SHARK OF JAPAN.

highest amount of nicotine necessarily tended to be the most injurious, no matter in what form it was smoked, but we now know that the form of smoking plays an important part. There was a theory that not in all three cases was the original nicotine in the tobacco conveyed as such to the mouth; sometimes it was destroyed by effective combustion, while at other times pyridine was responsible for toxic effects. According to this theory, which was all on the right track, the cigarette was least harmful, because the tobacco along the thin paper wrapper was exposed freely to the air, and as a consequence the tobacco was well burnt and all nicotine was destroyed. Against this it was held that in such a case one poison disappeared only for another one to be elaborated, and carbon monoxide was found in marked quantity as a poisonous constituent of cigarette smoke. As a mat- solid nucleus, separated by a thin stratum of liquid from the earth's crust, and rotating slightly less rapidly than the latter. According to Wehner's calculations, the nucleus makes a complete revolution, relatively to the surface of the earth, in 952 years. (There is room for a good deal of uncertainty in such calculations.) with protuberances which are centers of activity and that these protuberances, coming into contact with weak parts of the earth's crust, cause earthquakes and volcanic eruptions. From this theory and the records of earthquake shocks observed by navigators of th Atlantic Ocean during the last sixty years. Wehner concludes that a group of these formidable protuberance has now arrived under the region between 1 deg. and that danger is imminent in that part of the world. Wehner supposes, further, that the nucleus is studde 


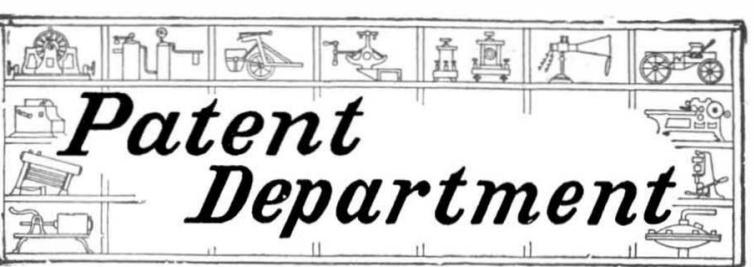

FIREPROOF $\triangle R C H$.

Pictured in the accompanying engraving is an arch used more particularly in fireproof work, which is of very simple construction. It consists of but two tile sections, each provided with an air space usually designated as a "vacuum." The usual I-beams be-

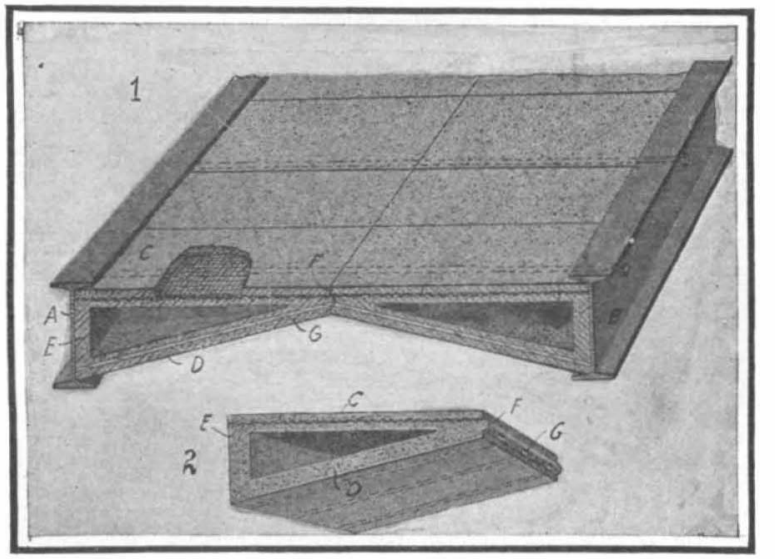

FIREPROOF ARCH.

tween which the arch is formed are indicated at $A$ and $B$. Each arch member comprises a top panel $C$, a bottom panel $D$ and a side panel $E$, thus giving the member the general shape of a wedge. At the poin of the wedge one of the members is provided with a tongue $F$, while the other member is formed with a groove adapted to receive this tongue. When the two sections are fitted between the I-beams they are thus interlocked. A weight placed on the interlocked tiles produces an Autward ppreading thrust againt the two I-beams $A$ and $B$. To resist this thrust the I-beams I-beams $A$ and $B$. To resist this thrust the I-beams
are braced by means of cross rods, as indicated by dotted lines in the illustration. Our illustration shows part of the upper panel of one of the sections broken away to reveal the reinforcing, which, in this case, consists of a netting of heavy iron or steel wire im bedded within the material. The lower panel is braced by means of bars $G$ imbedded therein which ex tend up into the tongue $F$. They take the end thrust and materially strengthen this portion of the arch The "vacuums" or wedge-shaped air spaces formed between the panels serve to prevent undue travel of hea through the arch in case of fire. A building having a large proportion of such arches is therefore to that extent rendered more nearly fireproof than would otherwise be the case. The inventor of this arch is Mr. Eugene F. Fitzpatrick, of 153 Withers Street, Brooklyn, N. Y.

\section{MOFFLER FOR TELEPHONE TRANSMITTERS.}

Unless one is using the telephone in a booth or in a quiet room it is impossible for him to exclude all local disturbing noises by stopping the ear that is not applied to the receiver, for the reason that the noises reach him by way of the transmitter of his own instrument. In order to eliminate all such disturbing sounds a very simple device has recently been invented which may be applied to any telephone transmitter. This device is illustrated in the accompany. ing engraving. It is extremely simple, consisting of two members hinged together, one of them being a ring-shaped plate adapted to be placed over the mouth of the transmitter, and provided with ears which are bent back over the outside of the transmitter. A wire band is then fitted over the ears, and the latter are bent upward and hooked over the wire. Owing

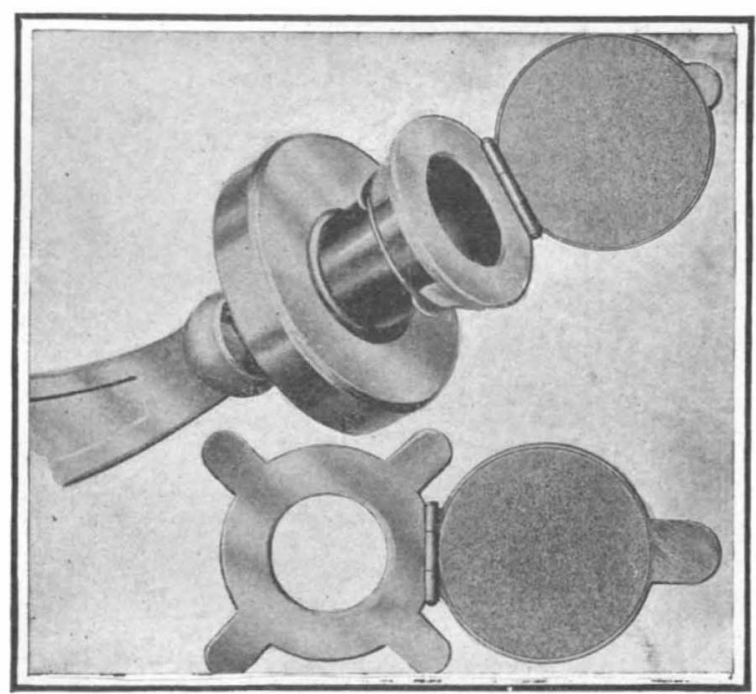

MOETLER FOR TELEPHONE TRANSMITTERS. to the outwardly flaring form of the transmitter the device is thus firmly made fast. Between the ring shaped plate and the transmitter is a strip of felt which serves to prevent vibrations that strike the plate from being communicated to the mouthpiece of the transmitter. The second member, which is hinged to the plate, is in the form of a flat cover provided on the inside with a lining of felt so that when it is closed down upon the other member it will exclude all sound from the transmitter. The hinged cover is provided with a finger piece, by which it may be opened whenever one desires to use the transmitter, but at all other times it should be closed to exclude ocal noises. The inventor of this simple attachment for telephone transmitters is William D. Plumb, 2022 Lexington Avenue, New York city.

\section{WROUGHT-STEEL SASHES}

In this the sanitary age we have come to recognize the importance of daylight in our work-rooms as well as in our homes. The germicidal effect of sunlight is well recognized. Add to this the fact that artificial light costs money, while sunlight is free, and nothing further need be said to demonstrate the superiority of the daylight shop, both from the sanitary and the economical point of view. Recently a new type of window sash has been devised for industrial buildings, which, it is claimed, by doing away with the cumbersome frames and heavy mullions makes it possible to deliver 25 per cent more light through a given opening than heretofore. The sash is of very simple construction, and yet is much stronger than the common wooden sash. It is better able to withstand the pressure of the wind, and furnishes no fuel to a fire. It is made of steel bars rolled to the cross section shown in the accompanying engraving. The method of joining these bars is very ingenious and decidedly unique. A small cross slot is made in the

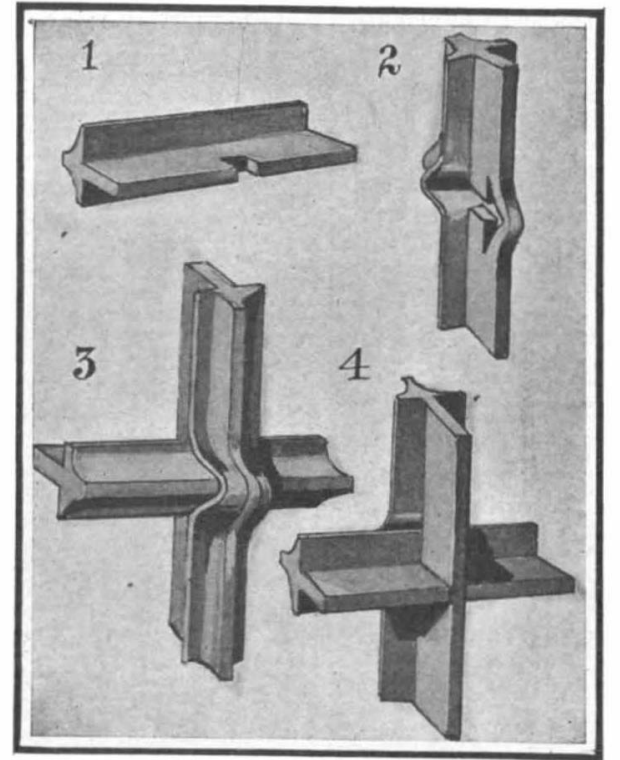

NOVEL JOINT FOR WRODGHT-STEEL SASHES.

vertical bar (Fig. 2) of the sash just large enough to admit the flange of the horizontal bar. The molded part of the vertical bar is then pressed out so as to fold closely around the molded portion of the horizontal bar, as shown in Fig. 3. In the latter bar a small notch is cut as indicated in Fig. 1 to act as a lock. It will be observed that the amount of metal removed in making this joint is inflnitesimal. The bars run without break from top to bottom of the window as well as from side to side, making a particularly strong framework, and this permits of using a much lighter section than is possible with a miter joint construction, so that a great saving is effected in the weight of the material used and consequently in the ultimate cost of the sash. Furthermore, the unusual type of joint makes a break in the monotony of the window sash, which is pleasing to the eye. A patent on this type of sash has been secured by the Detroit Steel Products Company of Detroit, Mich.

\section{SAFETY FUSE BLOCK}

Heretofore when fuses such as the screw plug, ordinary cartridge, or the open-wire type, have been used, it has been customary in making temporary ingtallations, requiring a larger capacity than supplied by the block used in the original installation, to remove the original fuse, and to substitute therefor one of larger and in many instances of a dangerously large carrying capacity. This has resulted in permitting a load to be introduced on the wires which has taxed and in some cases broken down the insulation by heat, resulting often in producing a dangerous fire. To obviate such possibilities the fuse block illustrated in the accompanying engraving has been devised. It is so arranged as to prevent the introduction between the terminals of a line, of a fuse having a larger carrying capacity than is designed for the line. The block $A$ as shown in
Fig. 1 is provided with a cylindrical compartment that opens at one end into a recess $B$, and at the other end communicates through a partition $I$ with a recess c. Each recess is fitted with a lug adapted to receive the terminal wires of the line. The lugs are engaged by screws that pass through the blocks and serve as binding posts to hold the line wires. The lug $D$ in the recess $B$ is provided with spring clips of accurate form adapted to grasp the body of the fuse $E$. The lug $F$ in the opposite recess is also provided with
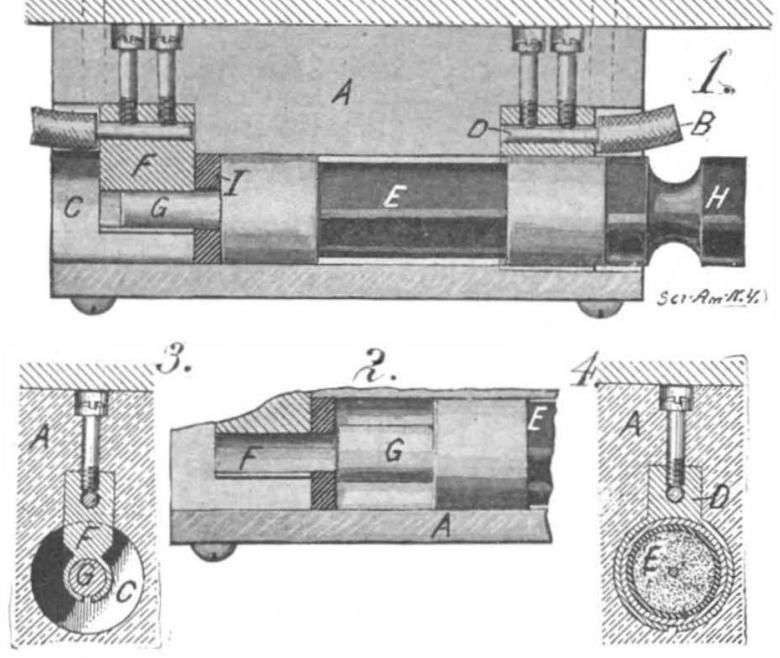

SAFETY FUSE BLOCR.

spring clips adapted to engage a boss $G$, which projects from the end of the fuse. The fuse is provided with the usual metallic contact bands, and one end is furnished with a handle $H$. All of the fuses adapted to be used with a block of a certain ampere carrying capacity are fitted with bosses of the same size. A fuse of larger carrying capacity, however, would have a boss of larger diameter. If one should attempt to insert a fuse of larger carrying capacity into the block the boss would fail to pass through the partition $I$ and enter the clip $F$ as shown in Fig. 2, and no contact would be made with the line terminals. The inventors of this electrical fuse block are Messrs. A. A Moffitt and G. E. Andrews, of 40 Bridgham Street Providence, R. I.

\section{ATTOMATIC STOCR-SALTING DEVICE.}

Cattle when housed or running free in a field need a limited supply of salt to maintain them in good condition. If the salt is placed in troughs mixed with feed some of the animals will prevent others from getting a proper amount of the salt. The accompanying engraving illustrates a device which affords free access to the stock for obtaining the requisite amount of salt and at the same time protects the salt from the elements and prevents waste. It consists of a cup shaped receptacle which is hemispherical, as indicated at $A$ in the illustration. $A$ cover piece $B$ is secured to the receptacle $A$ by means of screws which are threaded into lugs $C$ formed on the member $B$. The cover piece is also hemispherical in shape, but is cut away at the forward side to admit the muzzle of the animal. A hood $D$ is hinged to the cover $B$ and serves normally to close the opening in the latter. At the forward side of the hood is a lip $E$ which projects forward and is curved upward. The receptacle $A$ is provided with a similar lip $F$, which, however, is curved downward, thus leaving an opening which will expose the salt and attract the stock. In use a sufficient number of the salt holders are placed in the corral or the field where the stock range to enable the cattle to obtain the salt. The animal raises the hood by shoving his muzzle beneath the lip $E$ and rocking the hood back until it engages a lug $G$. When the animal withdraws his muzzle for the salt holder the hood will close by gravity, thus protecting the salt from exposure to the elements. Messrs. Frank and Thomas L. Peifer, of Beason, Ill. (R. F. D. No. 2) have recently secured a patent on this salting device.

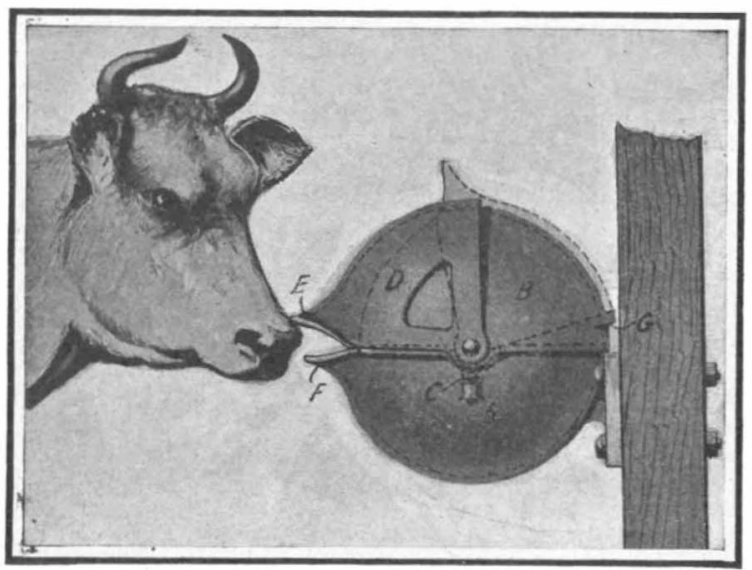

AUTOMATIC BTOCK-SALTING DEVICE. 